The increased success achieved with cadaveric transplantation makes it unethical to consider using a kidney from a young live donor, especially from a woman in the reproductive period of life. There may still occasionally be circumstances in which a kidney from a parent could reasonably be used, especially if the parent is old enough not to have responsibility for a young family. It is completely unjustified to use a kidney from an unrelated live donor, which offers no greater likelihood of success than a cadaveric kidney.

I am grateful to Mr. Joseph A. Kennedy, M.Ch., F.R.C.S., for permission to quote the details of his patient.

Mary G. McGeown, M.D., Ph.D., M.R.C.P. (Edin.) Consultant Medical Urologist Department of Nephrology Belfast City Hospital Lisburn Rd.

Department of Medicine Queen's University Belfast, N. Ireland

\section{REFERENCES}

1. Ackerman, J. R., Hopkinson, W. I., and Kenyon, J. R.: Successful 2448 hour canine kidney preservation, European Dialysis \& Transplant Association, 1967.

2. Belzer, F. O., Ashby, B. S., and Dunphy, J. E. 24-hour and 72-hour preservation of canine kidneys, Lancet 2:536, 1967 .

3. Franksson, C., Collste, L., Lundgren, G., Magnusson, G., and Wehle, B.: Kidney transplantations, 1964-66, at Serafimerlasarettet and St. Erik's Hospital, Stockholm, Scandinav. J. Urol. Nephrol. 1:81, 1967.

4. Kincaid-Smith, P., Marshall, V. C., Mathew, T. H., Eremin, J., Brown, R. B., Johnson, N., Lovell, R. R. H., McLeish, D. G., Fairley, K. F., Allcock, E. A., and Ewing, M. R.: Cadaveric renal transplantation, Lancet $2: 59,1967$.

5. Leake, C. D.: The changing mores of biomedical research, Ann. Int. Med. (Suppl. 7) 67:56, 1967.

6. Liljeqvist, L.: General health and renal function in kidney transplantation donors 8-30 months after nephrectomy, Scandinav. J. Urol. Nephrol. l:156, 1967 .

7. Murray, J. E., Barnes, B. A., and Atkinson, J.: Fifth report of the human kidney transplant registry, Transplantation 5:752, 1967 .

8. Starzl, T. E.: The changing mores of biomedical research, Ann. Int. Med. (Suppl. 7) 67:56, 1967.

\title{
Individual glomerular filtration rates in renovascular hypertension
}

\begin{abstract}
More than 30 years have passed since Goldblatt and associates $^{1}$ first reported the experimental production of persistent hypertension by producing renal ischemia. This communication was followed shortly thereafter by Butler's ${ }^{2}$ report of the first successfully treated case of renal hypertension by nephrectomy. While enthusiasm was initially great, it soon became apparent that fewer than 25 per cent of surgically treated patients were actually cured of hypertension which was presumably of renal origin. ${ }^{3}$ Better methods and criteria for the selection of surgical candidates were needed and differential renal function studies emerged as one of many methods to help the clinician select hypertensive patients with unilateral renovascular disease in whom a cure by surgical intervention might be expected.

The usefulness of differential renal function studies cannot be denied. The various methodology for their performance and criteria for their interpretation which have been introduced since the early work of Howard and associates ${ }^{4}$ and Connor and co-workers ${ }^{5}$ attests to the fact that no one method or criterion has been uniformly satisfactory in indicating which patients are ideal candidates for corrective surgery. Perhaps disappointment in differential renal function studies arises from the fact that as originally proposed $d^{4-8}$ they are all based upon an inherent fallacy; that is, they are comparative in nature and use as the standard for comparison
\end{abstract}

various parameters of function of the contralateral kidney (that opposite the kidney with suspected impaired arterial supply) which is arbitrarily designated as being "normal." Thus, in the presence of unsuspected bilateral renal disease, whether it is parenchymal or vascular or a combination of the two, the standard for comparison is often in error and unrecognized as such by the clinician. Before differential renal function studies can be meaningful and be relied upon as an aid for the selection of surgical candidates who may reasunably be expected to be cured of hypertension, adequate proof that the so-called "normal kidney" is in fact normal must first be cstablished.

$W^{9}$ recently studied 101 hypertensive patients by differential renal function studies, 23 of whom had unilateral main renal artery stenosis and were operated upon. Nine of the 23 patients were not surgically cured. All of the 14 patients who were cured by surgical procedures (revascularization or nephrectomy) had a positive differential renal function study by at least two of three criteria. ${ }^{4,6,7}$ Somewhat discouraging was the fact that the majority of those patients whose blood pressure did not respond to surgical treatment also had positive differential renal function studies. In 12 of the cured patients and in 7 of those who were not cured, an estimate of the glomerular filtration rate (GFR) of each kidney was made by calculating the endogenous 
creatinine clearance from urine and blood specimens obtained at the time of bilateral ureteral catheterization. It was apparent that, in those patients in whom the GFR in the contralateral kidney was normal or not reduced by more than 25 per cent of normal, a cure could reasonably be expected. By demonstrating that the "normal" kidney was indeed functionally normal, the predictive accuracy of differential renal function studies was substantially improved.

Vertes and associates ${ }^{10,11}$ have stressed the desirability of establishing that the "normal" kidney is in fact normal, using as their criterion normal tissue architecture observed in biopsy specimens obtained from the contralateral kidney. However, there is insufficient evidence to support the thesis that function precisely parallels architecture or that the pathological changes which are observed are totally irreversible. Indeed, it has been reported that surgical cures have been obtained in patients with unilateral main renal artery stenosis in whom reduced renal function was present in the contralateral kidney. ${ }^{12}$ This was true in one of our own patients. ${ }^{13}$ However, in five of our patients, in whom contralateral renal function was significantly impaired, a cure was not obtained regardless of whether the differential renal function study was positive by other criterion for unilateral renal artery stenosis.

Since differential renal function studies compare one kidney's function with that of the other, they are less accurate in the presence of bilateral disease, whether the disease is small or large vessel in nature. In our experience, the accuracy of differential renal function studies is greatly enhanced when an estimation of the glomerular filtration rate or renal plasma flow of each kidney is made at the time of bilateral ureteral catheterization. Stamey ${ }^{14}$ has pointed out the value of measuring the glomerular filtration rates or renal plasma flows of each kidney. We prefer the former, because of its relative simplicity and because we feel it more accurately reflects the intrarenal functional capacity.

Richard A. Schacht, M.D. Assistant Chief of Internal Medicine Research Associate United States Public Health Service Hospital New Orleans, La. James Conway, Ph.D., M.D. Associate Professor of Internal Medicine University of Michigan Medical Center Ann Arbor, Mich.

\section{REFERENCES}

1. Goldblatt, H., Lynch, J., Hanzal, R. F., and Summerville, W. W.: Studies on experimental hypertension. 1. The production of persistent elevation of systolic blood pressure by means of renal ischemia, J. Exper. Med. 59:347, 1934.

2. Butler, A. M.: Chronic pyelonephritis and arterial hypertension, J. Clin. Invest. 16:889, 1937.

3. Snith, H. W.: Hypertension and urologic disease, Am. J. Med. 4:724, 1948.

4. Howard, J. E., Berthrong, M., Gould, D. M. and Yendt, E. R.: Hypertension resulting from unilateral renal vascular disease and its relief by nephrectomy, Buil. Johns Hopkins Hosp. 94:51, 1954 .

5. Connor, T. B., Berthrong, M., Thomas, W. C., Jr., and Howard, J. E.: Hypertension due to unilateral renal disease: with a report on a functional test helpful in diagnosis, Bull. Johns Hopkins Hosp. 100:241, 1957.

6. Rapoport, A.: Modification of the "Howard Test" for the detection of renal artery obstruction, New England J. Med. 263:1159, 1960.

7. Stamey, T. A.: The diagnosis of curable unilateral renal hypertension by ureteral catheterization, Postgrad. Med. 29:496, 1961.

8. Birchall, R., Batson, H. M., Jr., and Brannan, W. Contribution of differential renal studies to the diagnosis of renal arterial hypertension, Am. J. Med. 32:164, 1962.

9. Schacht, R. A., Conway, J., and Stewart, B. H.: Split renal function studies in hypertension, Arch. Int. Med. 119:588, 1967.

10. Vertes, V., Grauel, J. A., and Goldblatt, H.: Renal arteriography, separate renal-function studies, and renal biopsy in human hypertension: selection of patients for surgical treatment, New England J. Med. 270:656, 1964.

11. Vertes, V., Genuth, S., Leb, D. E., and Galvin, J. B.: Unilateral renal plasma flow in the assessment of correctable rennvascular hypertension, New England J. Med. 273:855, 1965

12. Strickler, W. L.: Surgical treatment of renovascular hypertension, New England J. Med. 274:52, 1966.

13. Schacht, R. A., Zweifler, A. J., and Conway, J.: Renal artery stenosis, New England J. Med. $271: 55,1964$.

14. Stamey, T. A.: In Gross, F., editor: Antihypertensive therapy, Berlin, 1966, Springer-Verlag.

\section{Catecholamines and myocardial damage in scorpion sting}

Various species of scorpions have various kinds of poison that differ from one another in chemical structure and physiological effects. The effect of the sting depends upon the age of the scorpion, the season, and the size of the victim. ${ }^{1}$

Myocardial damage and heart failure are not a frequent complication in scorpion sting and have not been thoroughly investigated., Although the manifestations of scorpion venom are attributed to a neiurotoxic effect, the hasic merhanism of cardiac damage and congestive heart failure remains obscure. Furthermore, pathological observations of the cardiovascular system in fatal scorpion sting are scarce. ${ }^{4}$

Electrocardiographic abnormalities have been reported in some patients and attributed to a toxic 